Supporting Information for

\title{
Cancer Cell Detection on the Surface of Top Gated Monolayer Graphene via Raman
}

\section{Spectroscopy}

Sitansu Sekhar Nanda, ${ }^{a}$ Sandeep Kaushal, ${ }^{a}$ Yong Shin, ${ }^{b}$ Kyusik Yun, ${ }^{c}$ Seong Soo A. An, ${ }^{c}$ K. P. S. S. Hembram, ${ }^{d}$ Georgia C. Papaefthymiou, ${ }^{\mathrm{e}}$ Dong Kee $\mathrm{Yi}^{\mathrm{a}^{*}}$

aDepartment of Chemistry, Myongji University, Yongin, 03674, South Korea

bDepartment of Convergence Medicine, University of Ulsan College of Medicine Asan Medical Institute of Convergence Science and Technology (AMIST) Biomedical Engineering Research Center, Asan Medical Center, 88, Olympicro-43 gil, Songpa-gu, Seoul, 05505, South Korea 'Department of Bionanotechnology, Gachon University, Seongnam, 13120, South Korea ${ }^{\mathrm{d} O p t o e l e c t r o n i c}$ Materials and Devices Research Center, Korea Institute of Science and Technology (KIST), Seoul, 02792, South Korea

eDepartment of Physics, Villanova University, Villanova, PA, 19085, USA

* Correspondence: vitalis@mju.ac.kr

Synthesis and transfer of graphene: Synthesis, transfer of graphene and its bio-sensor device fabrication were clearly described in our previous publication. ${ }^{1}$ Briefly, LPCVD (Low Pressure Chemical Vapor Deposition) method was used for the synthesis of monolayer graphene. First, Ni etchant (Transene) was used for $\mathrm{Cu}$ foil $(25 \mu \mathrm{m}, 99.9 \%$, alfa aesar) cleaning ( $2 \mathrm{~min})$, washed with DI water (5 min) and for blocking oxidation nitrogen gas was used. The $\mathrm{Cu}$ foil was positioned in a 2 inch quart tube furnace. It was annealed at $1005^{\circ} \mathrm{C}$ under hydrogen flow $(99.999 \%$, $100 \mathrm{sccm}$ (standard cubic centimeter per minute)) (2 hours). Then, the hydrogen flow rate was used for growth of graphene. It was lessened to $30 \mathrm{sccm}$ and methane gas $(99.999 \%, 20 \mathrm{sccm})$ was inducted at total pressure of 0.5 torr for $60 \mathrm{~min}$ for growth of graphene. After the growth, graphene was transferred to $\mathrm{SiO}_{2}$ wafer using gold support transfer procedure.

A typical thermal evaporator was used for deposition of gold thin film (30nm). PMMA (Poly (methyl methacrylate) $(2 \mathrm{wt} \%$ in chrolobenzene) was spin-coated on gold/graphene on $\mathrm{Cu}$ foil at 500 r.p.m (5s) and then at 1,000 r.p.m. (30s). The PMMA layer was aged at room temperature (30min). In order to remove residual etchant, we etched the $\mathrm{Cu}$ foil in a liquid solution of copper 
etchant (Transene, CE-100) and washed it in DI water. After this, the stack was annealed at $60^{\circ} \mathrm{C}$ (60 min) in a dry oven to evaporate residual water. Later, the PMMA layer was molten in acetone while blowing with nitrogen gas. After PMMA removal, the gold layer was dissolved by the gold etchant (KI: I2: DI water solution). It was washed with ethanol and dried by nitrogen gas blowing.

Device fabrication: Graphene based biosensor device fabrication was executed as follows:

1) Gold supported transfer method was used for monolayer graphene on $\mathrm{SiO}_{2}$, as described above. 2) Electrodes were prepared with the graphene/ $\mathrm{SiO}_{2}$ wafer by using a hot plate, heated to a temperature of $160^{\circ} \mathrm{C} .3$ ). Afterwards, some indium was located on the graphene edge and melting of indium was observed (1 min). 4) Copper tape was connected to the indium above the graphene edge. For the indium to harden, it was stored at room temperature for a while.

(A)

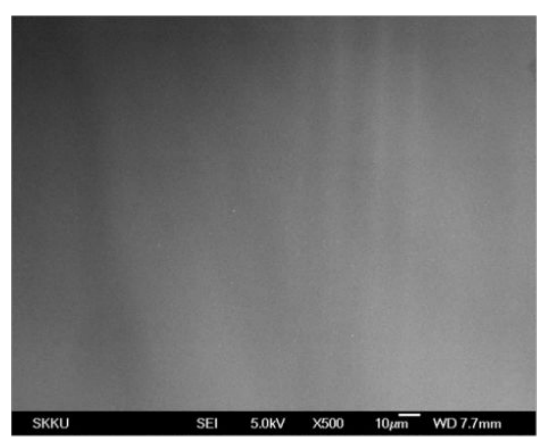

(B)

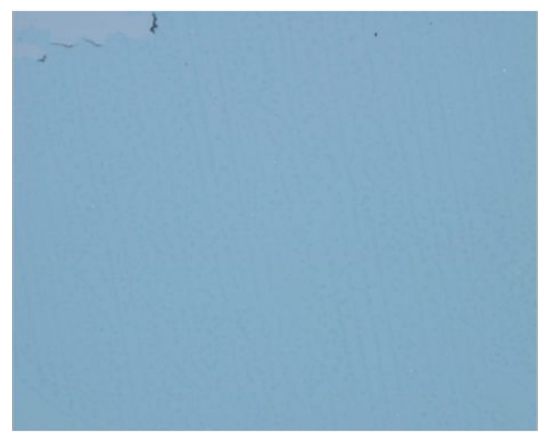

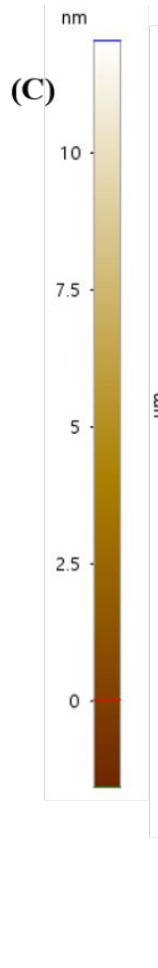

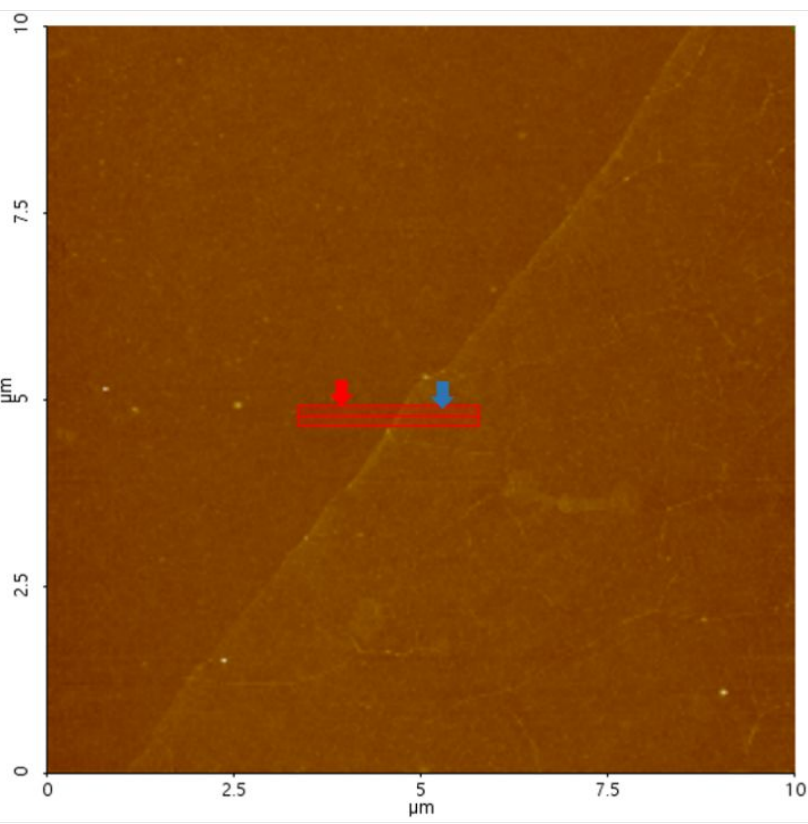

\begin{tabular}{|l|c|}
\hline Cursor & $\mathrm{Y}(\mathrm{nm})$ \\
\hline Red & 0.044 \\
\hline Blue & 0.405 \\
\hline
\end{tabular}

Measured

Thickness

$0.361 \mathrm{~nm}$

Figure-S1: Physical Characterization of monolayer graphene film grown by CVD. (A)

SEM image of full growth monolayer graphene film on copper foil. (B) Optical microscopy image of fully grown monolayer graphene, data (after transfer) on $\mathrm{SiO}_{2}$. (C) AFM image of fully grown monolayer graphene on $\mathrm{SiO}_{2}$ with $0.36 \pm 0.05 \mathrm{~nm}$ thickness using cross 
sectional analysis.
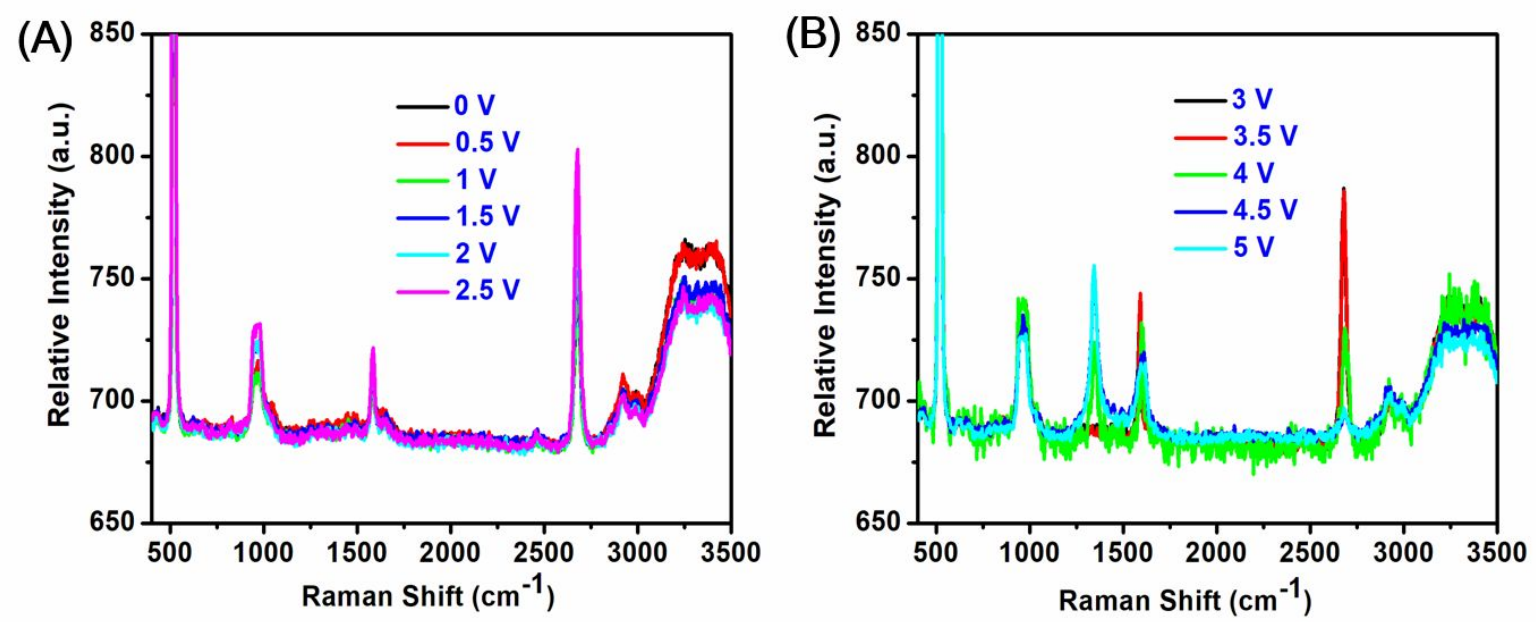

Figure-S2: Raman spectra of top gated monolayer graphene with skin cancer cells (SCC-7) and a voltage variation from (A) $0 \mathrm{~V}$ to $2.5 \mathrm{~V}$ and (B) $3 \mathrm{~V}$ to $5 \mathrm{~V}$. Peak observed at $1000 \mathrm{~cm}^{-1}$ assigned to Phenylalanine. C-H stretching bands were demonstrated at $2955 \mathrm{~cm}^{-1}$ and N-H stretching bands were demonstrated at $3440 \mathrm{~cm}^{-1}$. Simultaneously, G band $\left(1585 \mathrm{~cm}^{-1}\right), 2 \mathrm{D}$ band $\left(2700 \mathrm{~cm}^{-1}\right)$ and D band $\left(1350 \mathrm{~cm}^{-1}\right)$ are observed in this figure.
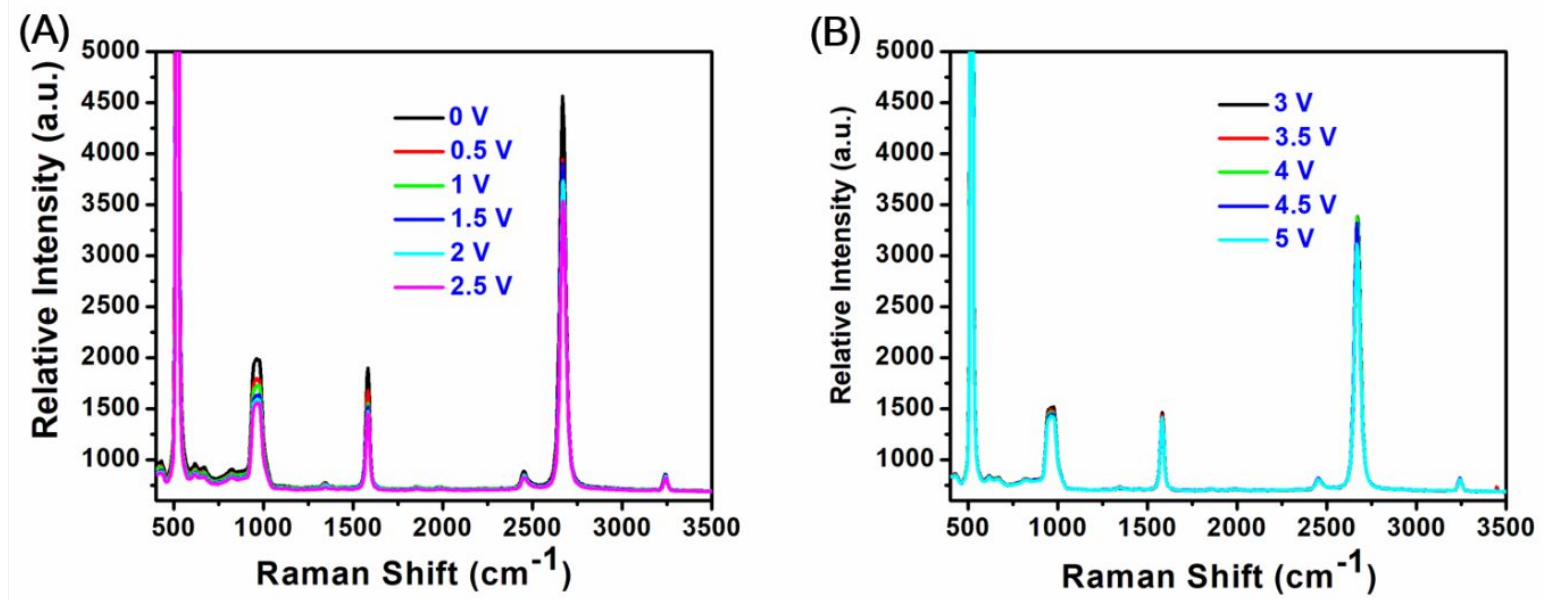

Figure- S3: Raman spectra of top gated monolayer graphene with breast cancer (MDAMB 231) cells and a voltage variation from (A) $0 \mathrm{~V}$ to $2.5 \mathrm{~V}$ and (B) $3 \mathrm{~V}$ to $5 \mathrm{~V}$. Peak observed at $1000 \mathrm{~cm}^{-1}$ assigned to Phenylalanine. C-H stretching bands were demonstrated at $2825 \mathrm{~cm}^{-1}$ and N-H stretching bands were demonstrated at $3440 \mathrm{~cm}^{-1}$. Simultaneously, $\mathrm{G}$ band $\left(1585 \mathrm{~cm}^{-1}\right), 2 \mathrm{D}$ band $\left(2700 \mathrm{~cm}^{-1}\right)$ and $\mathrm{D}$ band $\left(1350 \mathrm{~cm}^{-1}\right)$ are observed in this figure. 

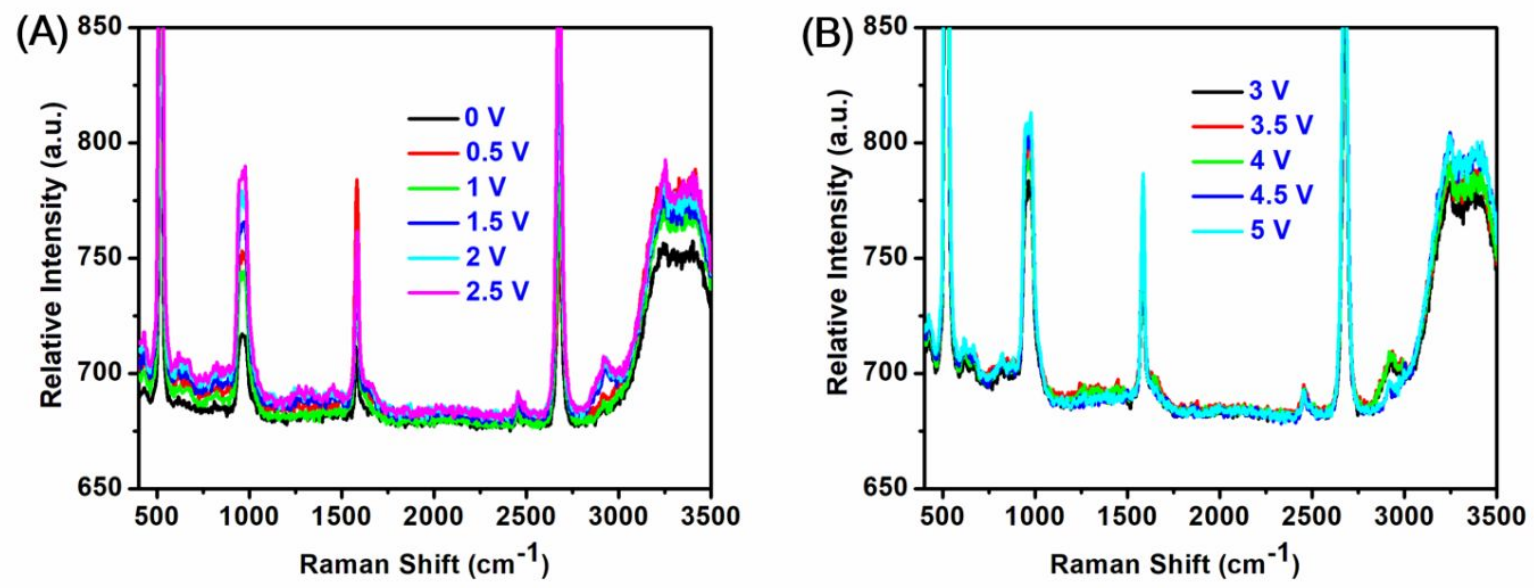

Figure- S4: Raman spectra of top gated monolayer graphene with breast (MDAMB 468) cancer cells and a voltage variation from (A) $0 \mathrm{~V}$ to $2.5 \mathrm{~V}$ and (B) $3 \mathrm{~V}$ to $5 \mathrm{~V}$. Peak observed at $1000 \mathrm{~cm}^{-1}$ assigned to Phenylalanine. C-H stretching bands were demonstrated at $2825 \mathrm{~cm}^{-1}$ and $\mathrm{N}-\mathrm{H}$ stretching bands were demonstrated at $3440 \mathrm{~cm}^{-1}$. Simultaneously, $\mathrm{G}$ band $\left(1585 \mathrm{~cm}^{-1}\right), 2 \mathrm{D}$ band $\left(2700 \mathrm{~cm}^{-1}\right)$ and $\mathrm{D}$ band $\left(1350 \mathrm{~cm}^{-1}\right)$ are observed in this figure.
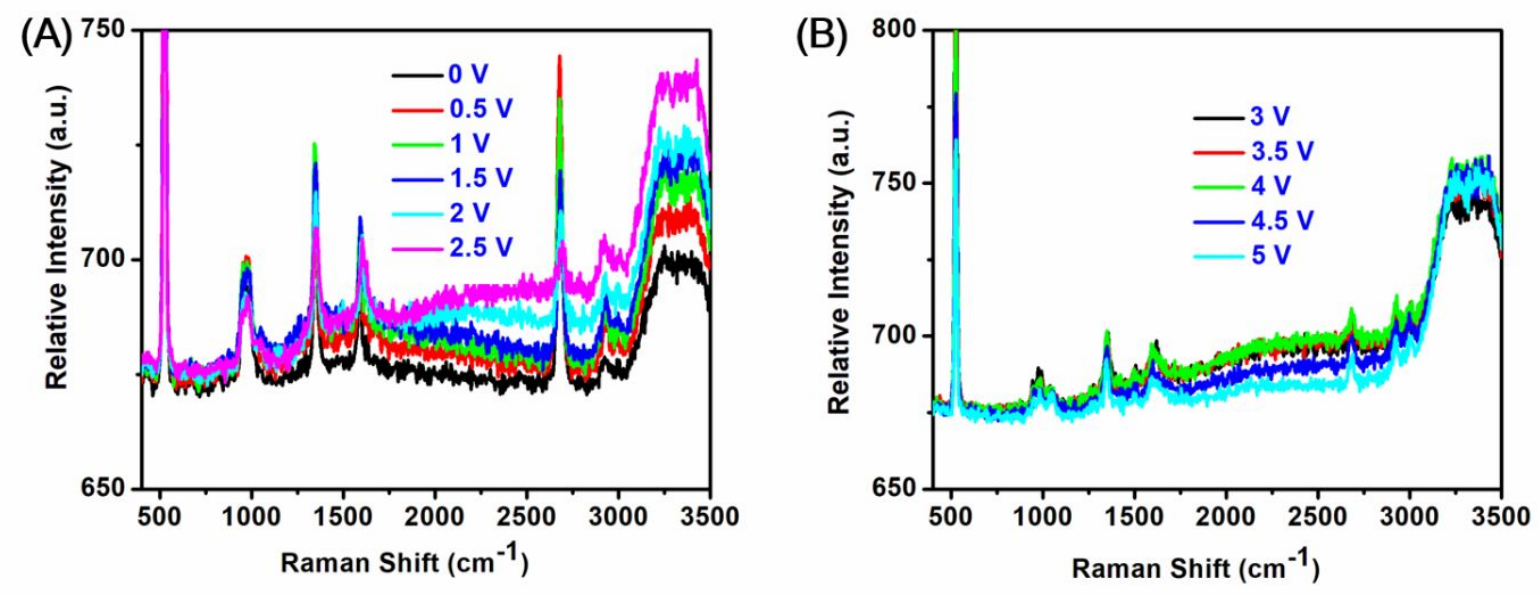

Figure- S5: Raman spectra of top gated monolayer graphene with liver (HepaRG) cells and a voltage variation from (A) $0 \mathrm{~V}$ to $2.5 \mathrm{~V}$ and (B) $3 \mathrm{~V}$ to $5 \mathrm{~V}$. Peak observed at $1000 \mathrm{~cm}^{-1}$ assigned to Phenylalanine. C-H stretching bands were demonstrated at $2825 \mathrm{~cm}^{-1}$ and $\mathrm{N}-\mathrm{H}$ stretching bands were demonstrated at $3440 \mathrm{~cm}^{-1}$. Simultaneously, G band $\left(1585 \mathrm{~cm}^{-1}\right), 2 \mathrm{D}$ band $\left(2700 \mathrm{~cm}^{-1}\right)$ and $\mathrm{D}$ band $\left(1350 \mathrm{~cm}^{-1}\right)$ are observed in this figure. 

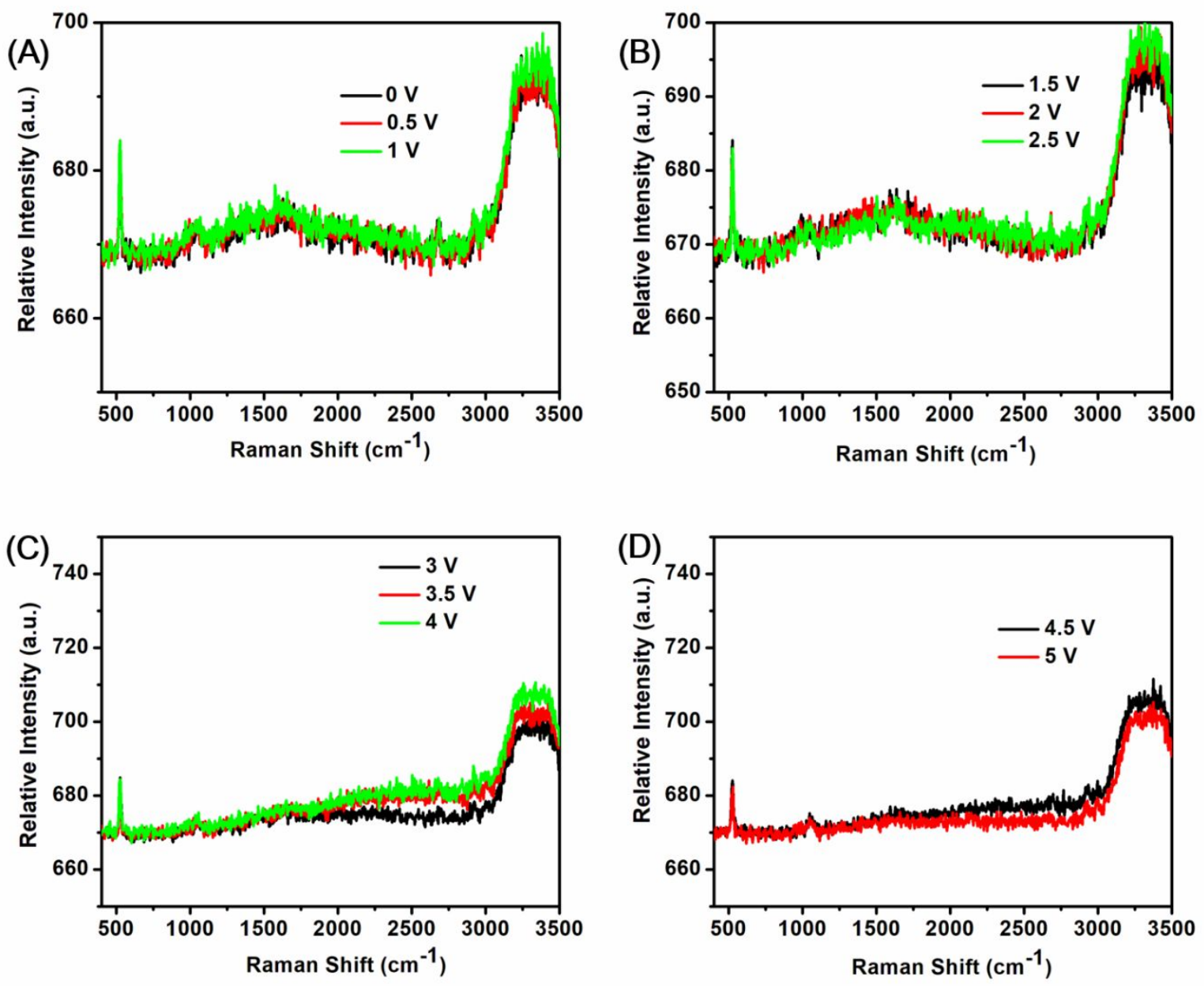

Figure- S6: Raman spectra of top gated monolayer graphene with liver (HepG2) cancer cells and a voltage variation from (A) $0 \mathrm{~V}$ to $1 \mathrm{~V}$, (B) $3 \mathrm{~V}$ to $4 \mathrm{~V}$ (C) 3 to $4 \mathrm{~V}$ and (D) $4.5 \mathrm{~V}$ to $5 \mathrm{~V}$. G band (1585 $\left.\mathrm{cm}^{-1}\right)$ and $\mathrm{D}$ band $\left(1350 \mathrm{~cm}^{-1}\right)$ are observed in this figure. 

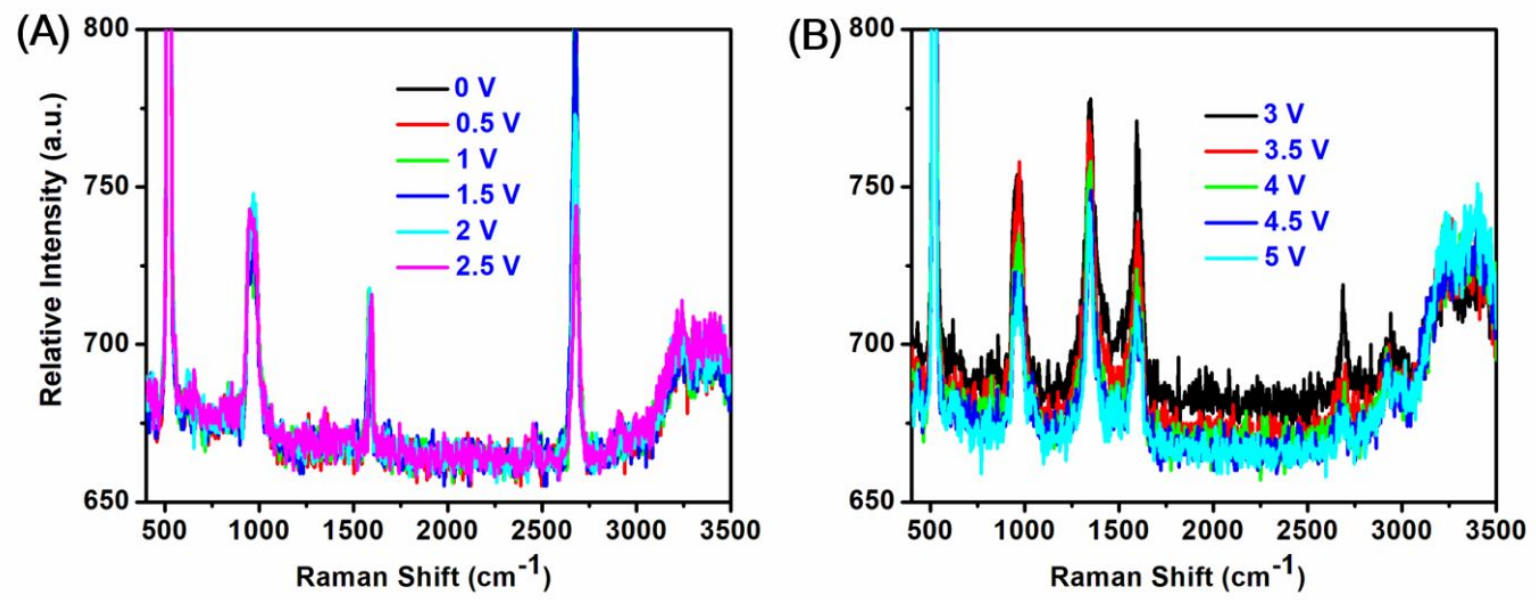

Figure- S7: Raman spectra of top gated monolayer graphene with colon (CCD 841) cells and a voltage variation from (A) $0 \mathrm{~V}$ to $2.5 \mathrm{~V}$ and (B) $3 \mathrm{~V}$ to $5 \mathrm{~V}$. Peak observed at $1000 \mathrm{~cm}^{-1}$ assigned to Phenylalanine. C-H stretching bands were demonstrated at $2825 \mathrm{~cm}^{-1}$ and $\mathrm{N}-\mathrm{H}$ stretching bands were demonstrated at $3440 \mathrm{~cm}^{-1}$. Simultaneously, G band $\left(1585 \mathrm{~cm}^{-1}\right), 2 \mathrm{D}$ band $\left(2700 \mathrm{~cm}^{-1}\right)$ and D band $\left(1350 \mathrm{~cm}^{-1}\right)$ are observed in this figure.
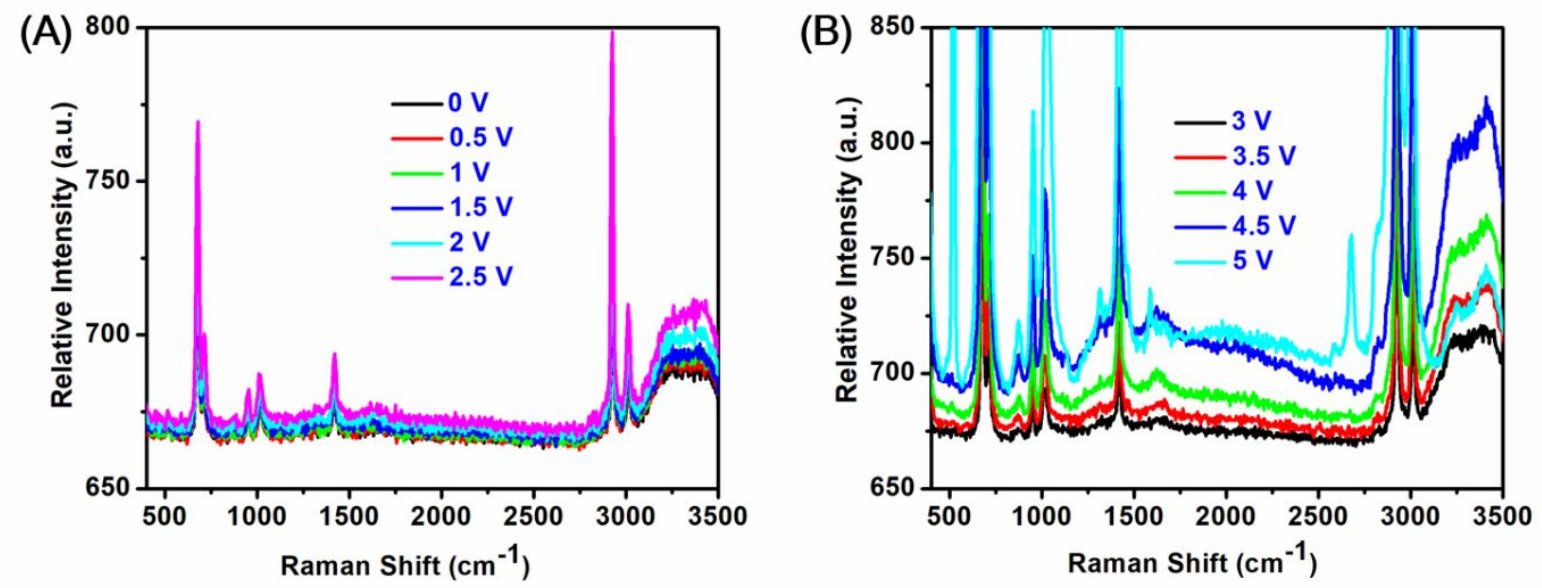

Figure- S8: Raman spectra of top gated monolayer graphene with normal (HEK293) cells and a voltage variation from (A) $0 \mathrm{~V}$ to $2.5 \mathrm{~V}$ and (B) $3 \mathrm{~V}$ to $5 \mathrm{~V}$. Peak observed at $1000 \mathrm{~cm}^{-1}$ assigned to Phenylalanine. C-H stretching bands were demonstrated at $2825 \mathrm{~cm}^{-1}$ and $\mathrm{N}-\mathrm{H}$ stretching bands were demonstrated at $3440 \mathrm{~cm}^{-1}$. Simultaneously, G band $\left(1585 \mathrm{~cm}^{-1}\right), 2 \mathrm{D}$ band $\left(2700 \mathrm{~cm}^{-1}\right)$ and $\mathrm{D}$ band $\left(1350 \mathrm{~cm}^{-1}\right)$ are observed in this figure. 

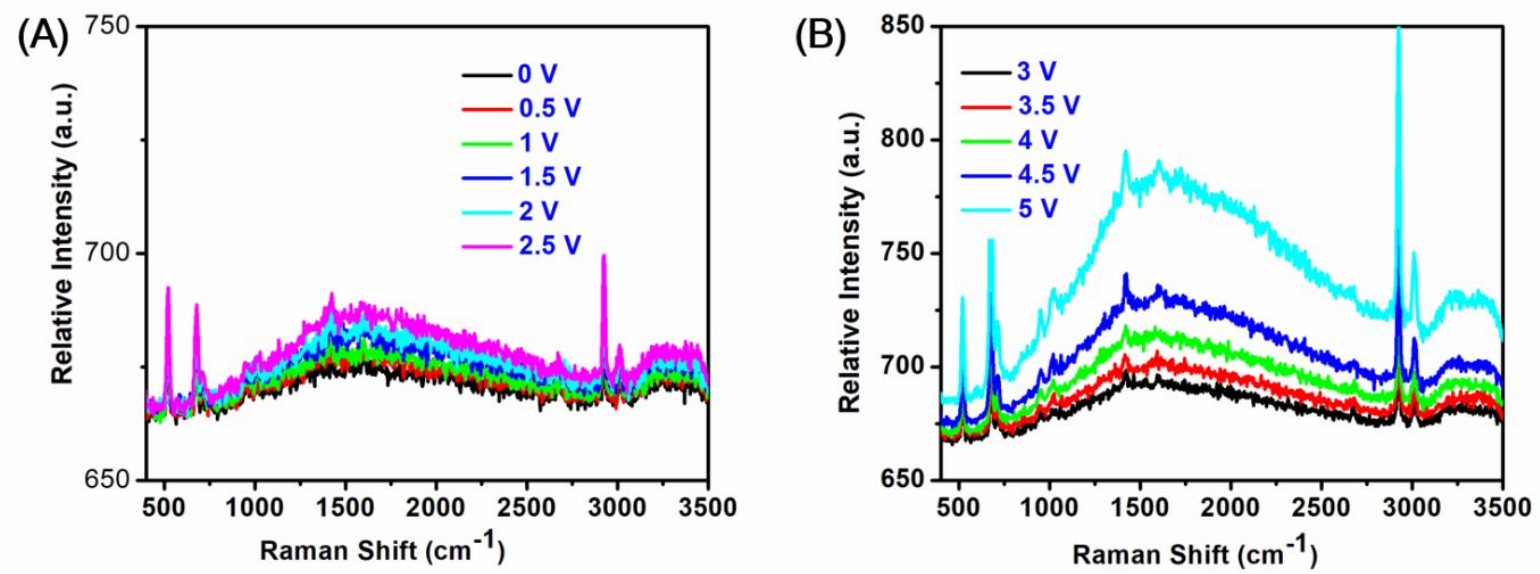

Figure- S9: Raman spectra of top gated monolayer graphene with normal (N9) cells and a voltage variation from (A) $0 \mathrm{~V}$ to $2.5 \mathrm{~V}$ and (B) $3 \mathrm{~V}$ to $5 \mathrm{~V}$. Peak observed at $1000 \mathrm{~cm}^{-1}$ assigned to Phenylalanine. C-H stretching bands were demonstrated at $2825 \mathrm{~cm}^{-1}$ and N-H stretching bands were demonstrated at $3440 \mathrm{~cm}^{-1}$. Simultaneously, G band $\left(1585 \mathrm{~cm}^{-1}\right), 2 \mathrm{D}$ band $\left(2700 \mathrm{~cm}^{-1}\right)$ and D band $\left(1350 \mathrm{~cm}^{-1}\right)$ are observed in this figure.
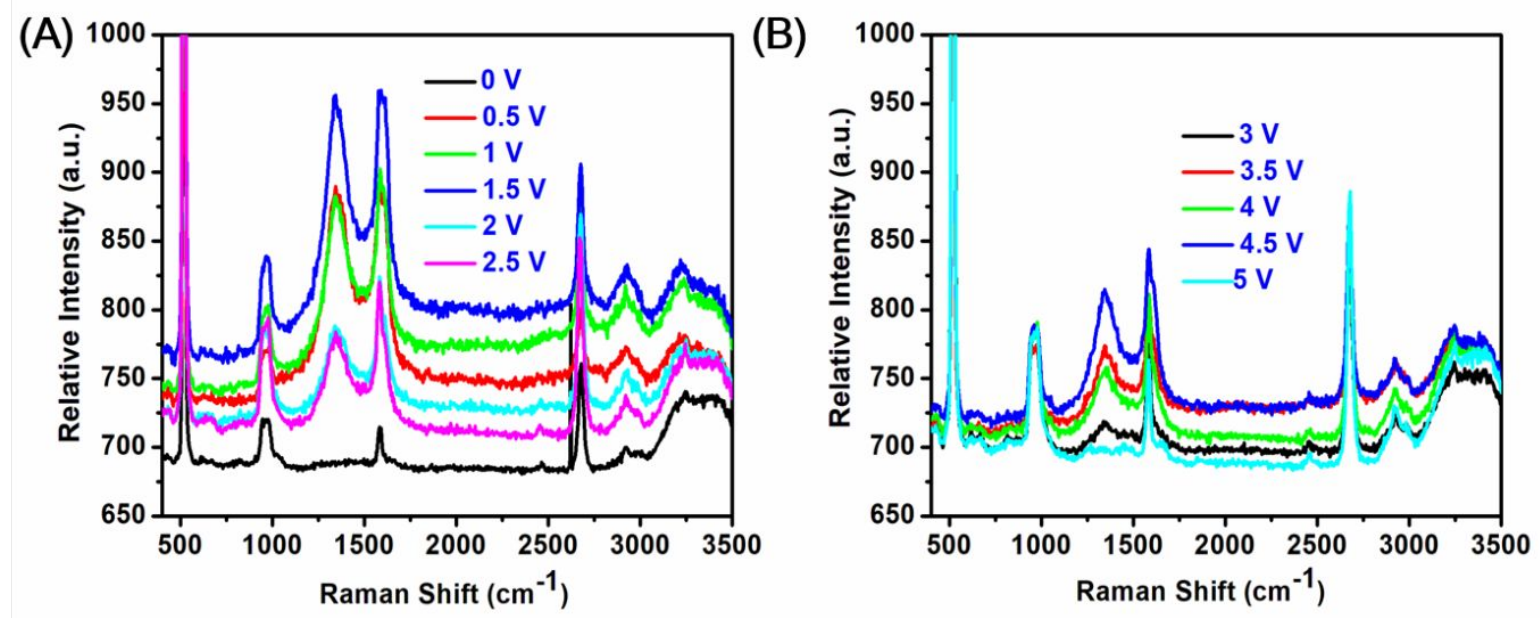

Figure- S10: This figure presents colon cancer cells (CT-26) with a voltage variation from (A) $0 \mathrm{~V}$ to $2.5 \mathrm{~V}$ and (B) $3 \mathrm{~V}$ to $5 \mathrm{~V}$. Peak at $1000 \mathrm{~cm}^{-1}$ attributed to Phenylalanine. C-H stretching bands are seen at $2825 \mathrm{~cm}^{-1}$ and $3210 \mathrm{~cm}^{-1}$. Simultaneously, $\mathrm{G}$ band $\left(1585 \mathrm{~cm}^{-1}\right), 2 \mathrm{D}$ band $\left(2700 \mathrm{~cm}^{-1}\right)$ and D band $\left(1350 \mathrm{~cm}^{-1}\right)$ are seen in this figure. 


\section{References:}

1. Nanda, S. S.; Kim, B. J.; Kim, K. W.; Nasir, T.; Park, J.; Yun, K.; Hembram, K. P. S. S.; Papaefthymiou, G. C.; Choi, J. Y.; Yi, D. K. A New Device Concept for Bacterial Sensing by Raman Spectroscopy and Voltage-gated Monolayer Graphene. Nanoscale, 2019, 11, 8528-8537. 